NASA Technical Memorandum 106619

\title{
Numerical Analysis of an Impinging Jet Reactor for the CVD and Gas-Phase Nucleation of Titania
}

Suleyman A. Gokoglu

Lewis Research Center

Cleveland, Ohio

Gregory D. Stewart

Ohio Aerospace Institute

Brook Park, Ohio

Joshua Collins and Daniel E. Rosner

Yale University

New Haven, Connecticut

Prepared for the 1993 Fall Meeting sponsored by the Materials Research Society

Boston, Massachusetts, November 29 - December 3, 1993

National Aeronautics and

Space Administration 


\title{
Numerical Analysis of an Impinging Jet Reactor for the CVD and Gas-Phase Nucleation of Titania
}

\author{
Suleyman A. Gokoglu \\ National Aeronautics and Space Adminstration \\ Lewis Research Center \\ Cleveland, ohio 44135 \\ Gregory D. Stewart \\ Ohio Aerospace Institute \\ 22800 Cedar Point Road \\ Brook Park, Ohio 44142 \\ Joshua Collins and Daniel E. Rosner \\ Yale University \\ Chemical Engineering Department \\ New Haven, Connecticut 06520-8286
}

\section{ABSTRACT}

We model a cold-wall atmospheric pressure impinging jet reactor to study the CVD and gas-phase nucleation of $\mathrm{TiO}_{2}$ from a titanium tetra-iso-propoxide (TTIP)/oxygen dilute source gas mixture in nitrogen. The mathematical model uses the computational code FIDAP and complements our recent asymptotic theory for high activation energy gas-phase reactions in thin chemically reacting sublayers. The numerical predictions highlight deviations from ideality in various regions inside the experimental reactor. Model predictions of deposition rates and the onset of gas-phase nucleation compare favorably with experiments. Although variable property effects on deposition rates are not significant ( $11 \%$ at $1000 \mathrm{~K})$, the reduction of rates due to soret transport is substantial ( $75 \%$ at $1000 \mathrm{~K})$.

\section{INTRODUCTION}

Production of sophisticated materials with superior properties by CVD requires an understanding of coupled transport and chemical processes. This goal can be realized in research programs by combining both experiments and modeling.

Recent Yale University research focused on $\mathrm{TiO}_{2}$ CVD with simultaneous gas-phase reaction leading to particle nucleation [1-2] . A simple asymptotic theory treated the onset of reactions leading to particle nucleation and reduced CVD rates at high surface temperatures. The theory assumed that all gas-phase reactions are restricted to a thin chemical sublayer adjacent to a hot CVD surface due to their large activation energies. They also developed a labscale, cold-wall, impinging jet CVD reactor [3]. Using experiments and appropriate asymptotic and numerical models, we expect to guide future reactor designs and scale-up, resulting in maximum cVD rates 
while avoiding harmful particle nucleation.

The present axisymmetric, numerical model points to the role of bouyancy and recirculation in the experimental reactor and clarifies the effect of soret transport in modifying TTIP mass transfer rates. It provides the ability to capture the transition from surface kinetics to gas-phase transport control. Furthermore, it extends the earlier asymptotic theory [1] by removing the restriction that the activation energies of gas-phase reactions should be "large" (i.e. the chemical sublayer should be "thin").

For the case studied at Yale [1-3] for the CVD of $\mathrm{TiO}_{2}$ from dilute TTIP $/ \mathrm{O}_{2}$ in $\mathrm{N}_{2}$, the ratio of chemical sublayer to thermal boundary layer thickness is estimated to be $1 / 5$ at the onset of particle nucleation $(\mathrm{T} \simeq 1050 \mathrm{~K})$, which may be too large for the accuracy of the asymptotic theory. Hence, our numerical model may ultimately be better able to capture the effects of homogeneous chemistry leading to an observed deposition rate fall-off above $\sim 1050 \mathrm{~K}$.

\section{EXPERIMENT}

We use a cold-wall, atmospheric pressure, axisymmetric, impinging-jet reactor (Fig. 1). The liquid TTIP source is a constant temperature bubbler. After mixing TTIP vapor with excess oxygen (to "burn away" any co-deposited carbon) and diluting with nitrogen in a short mixing chamber, the gas jet emerges from a converging nozzle and impinges on a polished quartz substrate (diam. $1.3 \mathrm{~cm}$ ). The substrate and the alumina substrate holder are supported from below by an RF-heated graphite susceptor. The susceptor temperature is measured using a Pt $-30 \% \mathrm{Rh} / \mathrm{Pt}-6 \% \mathrm{Rh}$ thermocouple just below the substrate. This thermocouple reading is correlated with direct substrate surface temperature measurements made in situ using known melting point lacquers (with $\sim 3-4 \%$ accuracy). Gas and surface temperatures at several other locations are also measured by thermocouples. The concentration of water vapor in the reactor is less than $3 \mathrm{ppm}$. Deposition rates are measured by in situ interferometry and confirmed by ex situ weight gain. Further details of the experimental system and operating procedure are given in [3].

\section{PHYSICO-CHEMICAL/NUMERICAL MODEL}

our modeling study adopts the finite-element-based computational fluid dynamics code FIDAP. The new version of FIDAP incorporates many phenomena relevant to CVD processes, such as temperature dependent fluid density, transport and thermodynamic properties, soret diffusion, and gas-phase and surface chemical reactions.

We approximate the reactor by using a 2-D axisymmetric geometry (Fig. 2). The inlet and exit are placed sufficiently far from the deposition zone to eliminate numerical uncertainties on rate predictions. The numerical mesh above the substrate is fine enough to resolve the chemical sublayer. Temperature boundary conditions are interpolations of measured surface temperatures in the Yale 
axisymmetric impinging jet reactor.

We assume that the gas-phase decomposition of TTIP is first order with a rate constant of $3.96 \times 10^{5} \exp (-8480 / \mathrm{T}) \mathrm{s}^{-1}$ ( $\mathrm{T}$ is in Kelvins) [4]. We also assume that the gas-phase products form nondepositing particles. We fit our low substrate temperature rate data to a Soret-corrected Arrhenius expression, $1.21 \times 10^{9} \exp (-16480 / \mathrm{T})$ $\mathrm{m} / \mathrm{s}$, to obtain a pseudo-first order surface reaction rate constant. This expression corresponds to a TTIP reactive sticking probability of unity at $987 \mathrm{~K}$. For simplicity, the surface reaction rate constant is kept at its $987 \mathrm{~K}$ value for higher substrate temperatures so that the sticking probability does not exceed unity.

The soret diffusion factor for dilute TTIP in $\mathrm{N}_{2}$ is calculated from kinetic theory (the estimated Lennard-Jones parameters for TTIP are $\sigma=8.13 \AA$ and $\epsilon / \mathrm{k}=589 \mathrm{~K})$ and fitted to the expression $\alpha_{\mathrm{T}}=1.971[1-(223.6) / \mathrm{T}]$. Unfortunately, FIDAP is currently restricted to constant soret diffusivities, $D_{T}=\rho D \omega \alpha_{T}$, hence we evaluate the gas $\left(\mathrm{N}_{2}\right)$ density $\rho$, TTIP Fickian diffusivity $D$, and $\alpha_{T}$ at $T_{\text {film }}=\left(T_{\text {nozzle }}+T_{\text {surface }}\right) / 2$, and use the TTIP mass fraction $\omega$ at the $T_{\text {film }}$ location for the corresponding diffusion limit calculation.

\section{RESULTS AND DISCUSSION}

First, we compare FIDAP predictions to the observed flow field inside the reactor. The experiments use argon seeded with fine titania particles for flow visualization. Figure 3 shows a typical comparison at a Reynolds number of 750 based on nozzle diameter at STP and $900 \mathrm{~K}$ substrate temperature. Indeed, FIDAP can demonstrate recirculations a) as the jet emerges from the nozzle due to flow separation, and b) on the sides of the hot susceptor due to bouyancy-induced convection. These recirculations are not detrimental because from the photograph one can see that particles trapped in the recirculation regions do not diffuse into the reagent jet, and we estimate that reaction product vapor species are also unable to penetrate appreciably into the jet. The Richardson number based on nozzle to substrate distance is 0.07 for this case. Lower flow rate $(\mathrm{Re}<100)$ measurements at higher substrate temperatures are hampered by buoyancy effects in the jet above the substrate. We discuss elsewhere [5] the operating conditions needed to avoid bouyancy-induced convection in such reactors. Our numerical analysis is capable of handling such non-ideal behavior.

For the results discussed below we fix the gas flow rate at 5160 sccm (Re $\simeq 500$ for $\mathrm{N}_{2}$ ) and the substrate-temperature-based TTIP concentration at $C_{s}=2.5 \times 10^{-6} \mathrm{Kgmol} / \mathrm{m}^{3}$. Deposition rates are reported as effective reaction probabilities $\epsilon$ defined as $\epsilon=n " /\left[(1 / 4) \mathrm{VC}_{\mathrm{s}}\right]$, where $\mathrm{n}^{\prime \prime}$ and $\mathrm{v}$ are the molar flux and mean thermal speed of TTIP, respectively, evaluated at the surface.

Figure 4 depicts soret diffusion and temperature-dependent gas transport-property effects on predicted rates at the stagnation point for transport controlled conditions. The rate reduction due to soret transport is $>75 \%$, whereas the effect of variable properties is $<15 \%$, for $\mathrm{T}>1000 \mathrm{~K}$. 
The model predicts reasonable deposition rates over the entire regime from surface kinetics to transport control by incorporating the surface kinetics extracted from our experiments (Fig. 5). With the gas-phase kinetics of [4], the model agreement with experiment is less satisfactory, though with similar trends. As the depletion of TTIP by the gas-phase reaction increases (i.e. chemical sublayer gets thicker) at higher substrate temperatures, thereby decreasing the TTIP surface flux (CVD rate), FIDAP's handling of soret transport becomes more inconsistent. This is because the constant $D_{T}$, used by FIDAP as defined above for the calculation of soret transport, does not exhibit the expected diminishing soret contribution as TTIP concentration diminishes. Hence, our rate predictions with Soret effect above substrate temperatures of $1200 \mathrm{~K}$ are not shown. The cause(s) of our underprediction of the steepness of the high temperature rate fall-off is currently under investigation.

The onset of homogeneous nucleation is inferred from a sudden drop in deposition rate at a certain substrate temperature. The reliability of the asymptotic theory prediction of this temperature depends on whether the chemical sublayer is indeed "much" thinner than the thermal boundary layer at the prevailing conditions. Figure 6 depicts the TTIP mass fraction profiles calculated by FIDAP at the stagnation point at a substrate temperature of $1200 \mathrm{~K}$ with and without gas-phase reaction. We also plot the difference between the two mass fraction curves to demonstrate the extent of gas-phase reaction, as well as the corresponding temperature profile. The predicted rate at this temperature with gas-phase chemistry is observably lower than the one without gas-phase chemistry. If the peak of this curve is taken as a measure of the thickness of the chemical sublayer, it is substantial (30\%) compared with the thermal boundary layer thickness. The amplitude and width of the difference curve would be larger at even higher substrate temperatures. Therefore, under such conditions predictions of the full numerical approach are expected to be more reliable than predictions of the simple asymptotic theory. Also noteworthy is the slight "enrichment" in the mass fraction profiles away from the surface due to the soret effect.

Figure 7 shows that the predicted rates on the susceptor are not uniform in the radial direction beyond the substrate radius $(6.35 \mathrm{~mm}$ vs. $16 \mathrm{~mm}$ for the susceptor). However, because the deposition rate is roughly uniform across the substrate, we have compared rate measurements to stagnation point rate predictions (Figs. 4 \& 5).

\section{CONCLUSIONS}

Our numerical model can correctly describe the flow field in our experimental atmospheric pressure, impinging jet reactor used for studying the CVD and gas-phase nucleation of titania. The model points to some buoyancy and flow recirculation effects inside the hot substrate reactor affecting the "ideal" stagnation point flow behavior. It can guide the interpretation of deposition rate measurements over a substrate temperature range (600-1400K) covering 
surface-kinetics-, gas-phase transport-, and gas-phase reactiongoverned regimes. Soret transport effects on predicted rates [6] are significant ( $75 \%$ reduction at $1000 \mathrm{~K})$, but variable property effects are modest $(<15 \%)$. Our numerical model extends the capability of the earlier asymptotic theory to predict the onset temperature of nucleation and the associated reduced deposition rates to include conditions where the chemical sublayer is not "much" thinner than the thermal boundary layer. Future work will include effects of flow rate and TTIP concentration [7], and a more careful examination of the high temperature rate fall-off regime.

\section{REFERENCES}

1. D.E. Rosner, J. Collins and J.L. Castillo, Proc. Twelfth Int. Symp. on Chemical Vapor Deposition, edited by K.F. Jensen and

G.W. Cullen, Proc. Vol. 93-2 (The Electrochem. Soc., Pennington, NJ, 1993), p. 41; also J.L. Castillo and D.E. Rosner, Yale Univ., HTCRE Lab. Publ. \#196, June 1993, to be submitted.

2. J.' Collins, D.E. Rosner, and J. Castillo, in Chemical Vapor Deposition of Refractory Metals and Ceramics II, edited by

T.M. Besmann, B.M. Gallois and J.W. Warren (Mater. Res. Soc.

Symp. Proc. , 250, 1992) pp. 53.

3. J. Collins, PhD Dissertation, Yale University, Department of Chemical Engineering, May 1994.

4. K. Okuyama, et al., AIChE J. 36 (3), 409 (1990).

5. G.D. Stewart, et al., in preparation, 1993.

6. Rosner, D.E. Transport Processes in Chemically Reacting Flow Systems, Butterworth-Heinemann, Stoneham, MA, 3rd Print, 1990.

7. K.L. Siefering and G.L. Griffin, J. Electrochem. Soc. 137 (3), 814 (1990); ibid., 137 (4), 1206 (1990). 


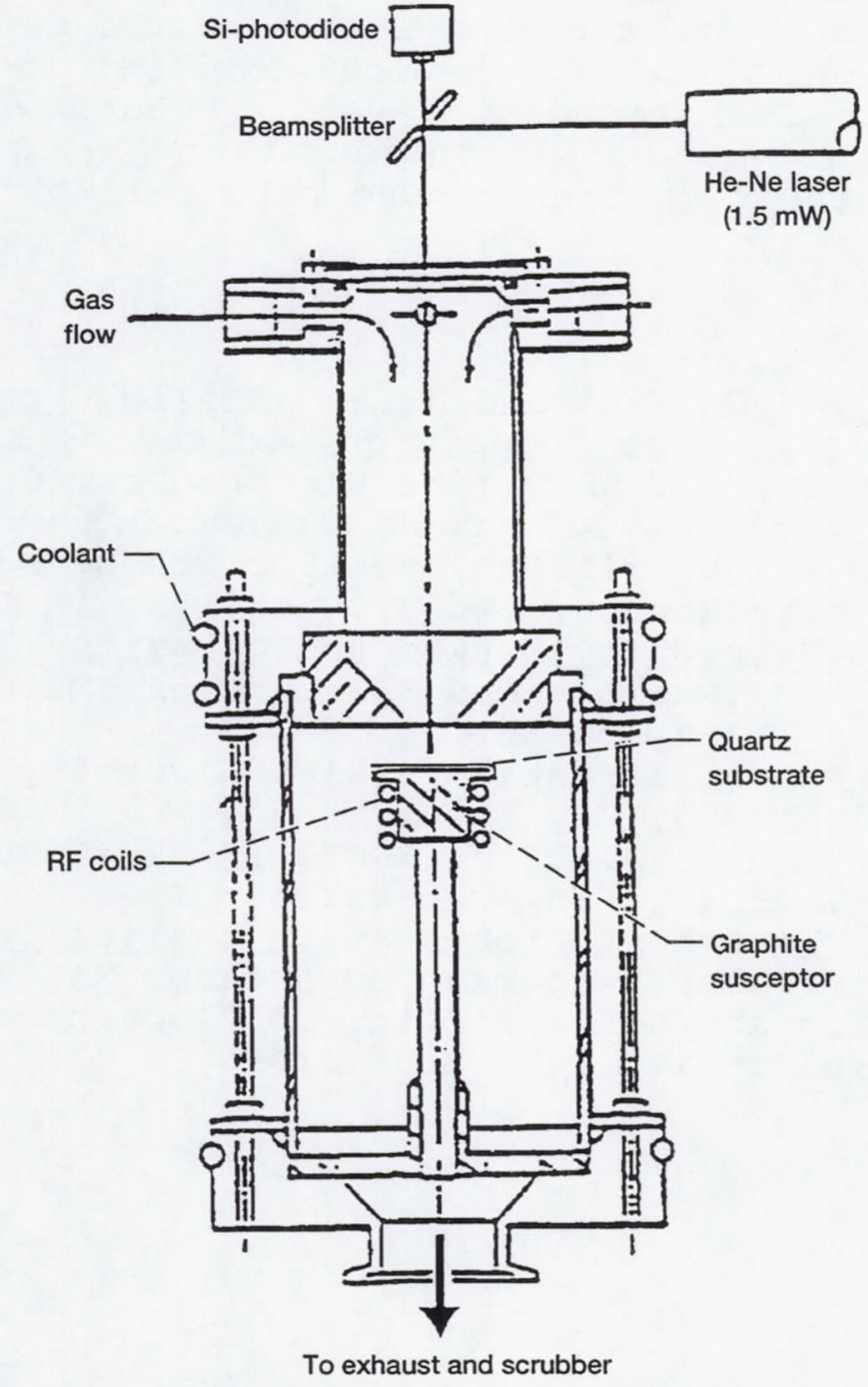

Figure 1. -Schematic of the experimental reactor, after [1]. 


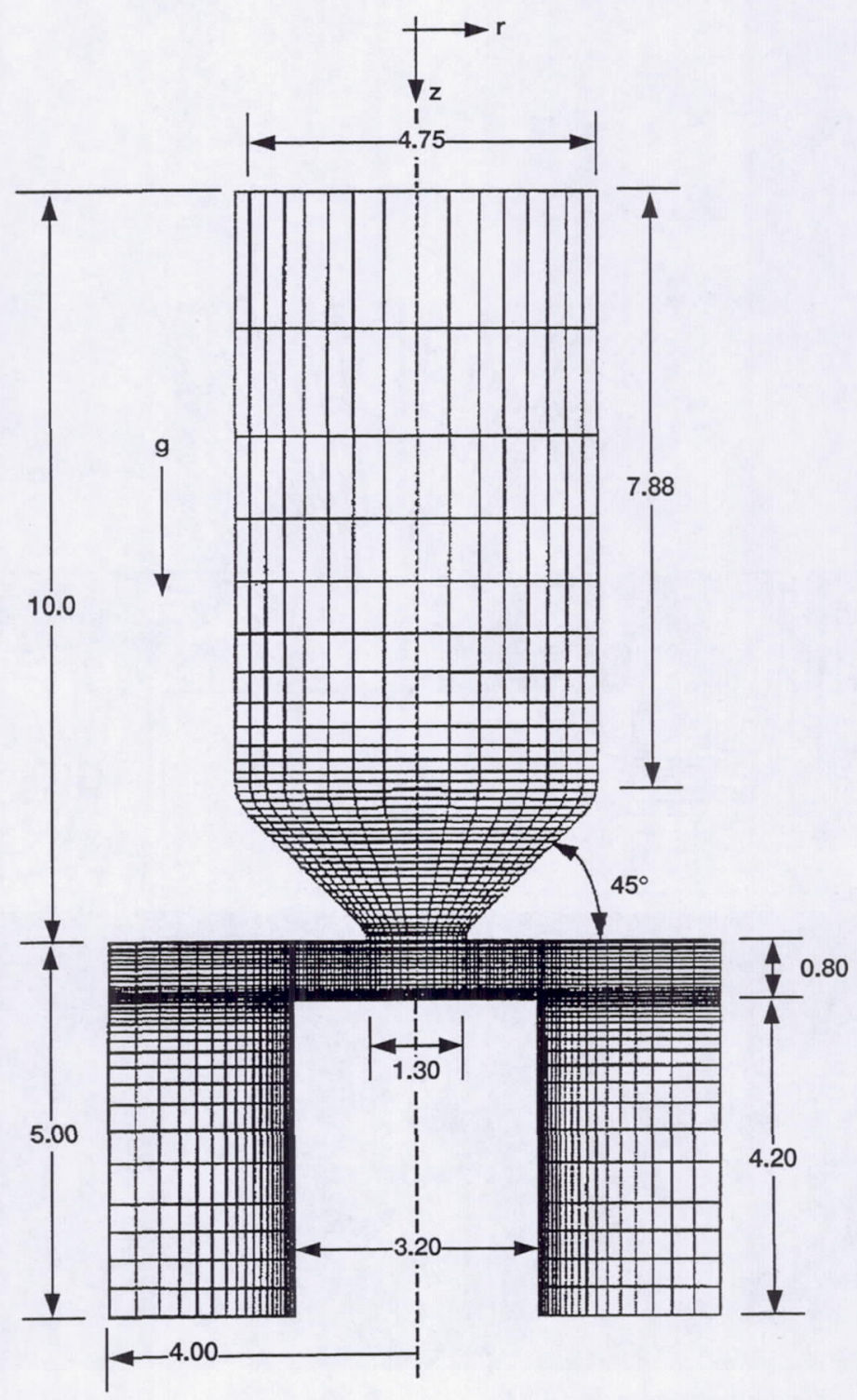

Figure 2.-The computational domain. All dimensions in centimeters, $\mathrm{cm}$ and angles in degrees. 


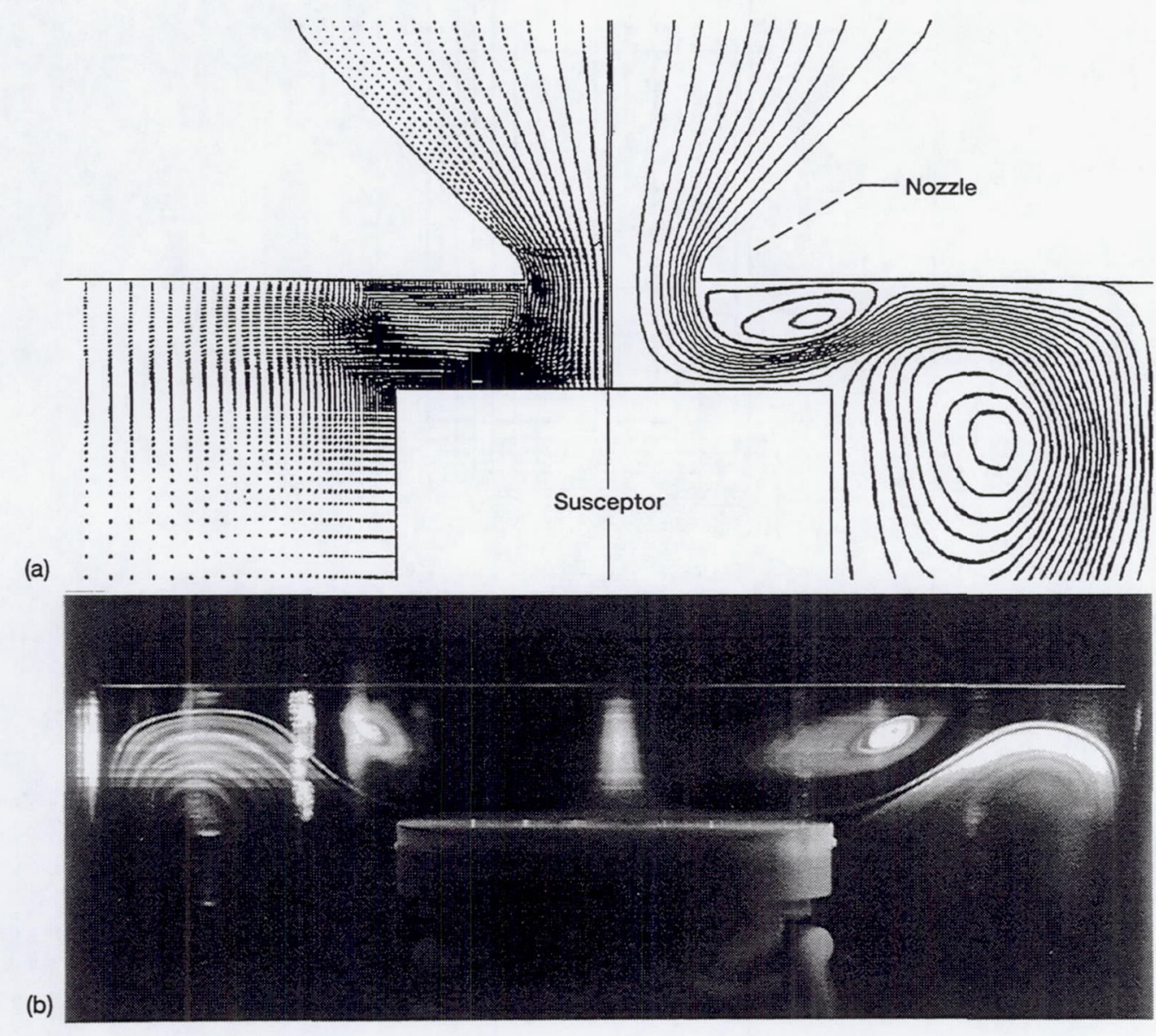

Figure 3.-Flow field for argon at $\mathrm{Re}=750 ; \mathrm{T}_{\text {substrate }}=900 \mathrm{~K}$. (a) FIDAP simulation (gas velocity vector/ streamline contours). (b) Experimental visualization with titania seed particles. 


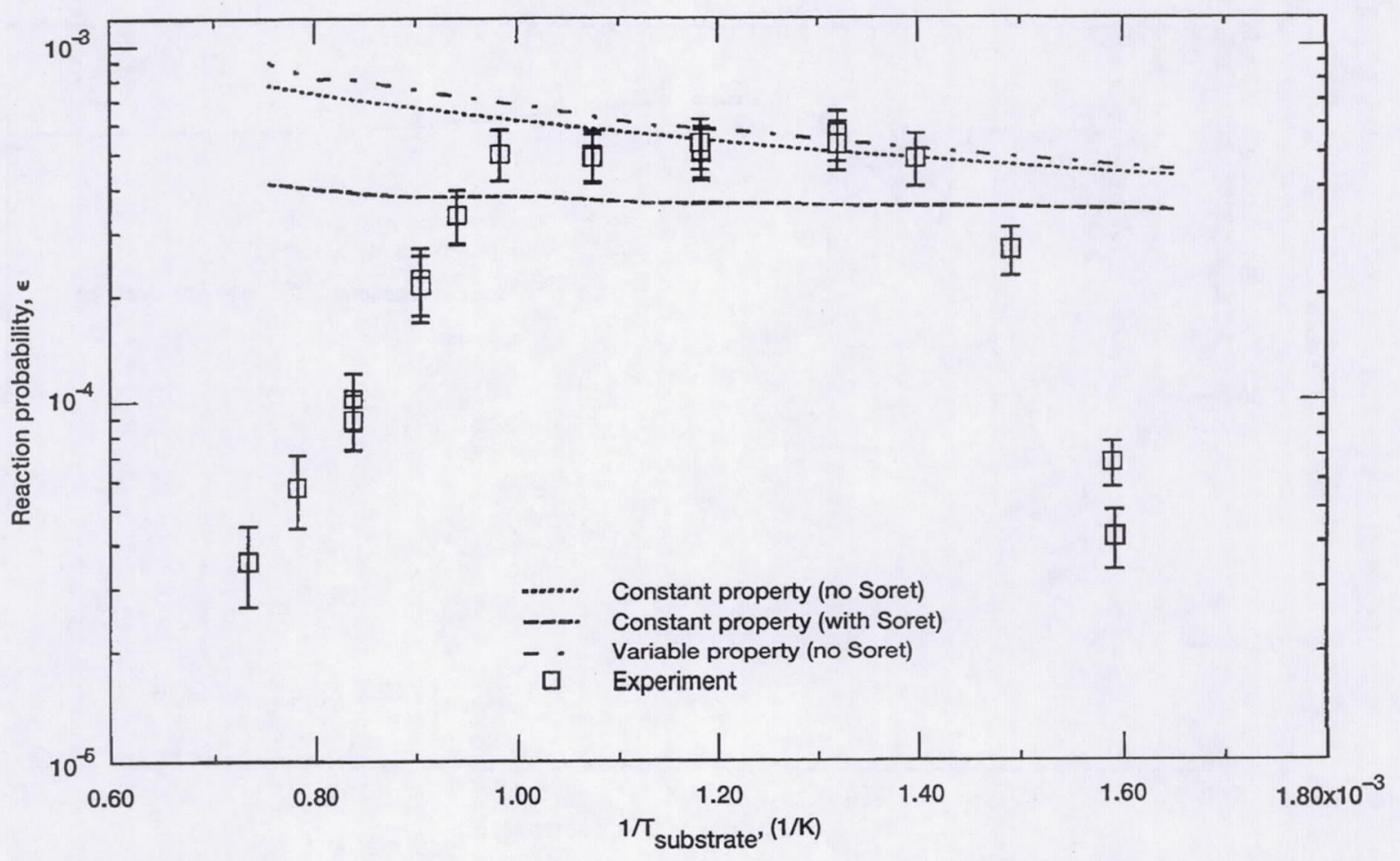

Figure 4.-Predicted deposition rates with diffusion limitations showing variable property and Soret effects. Experimental data shown for reference.

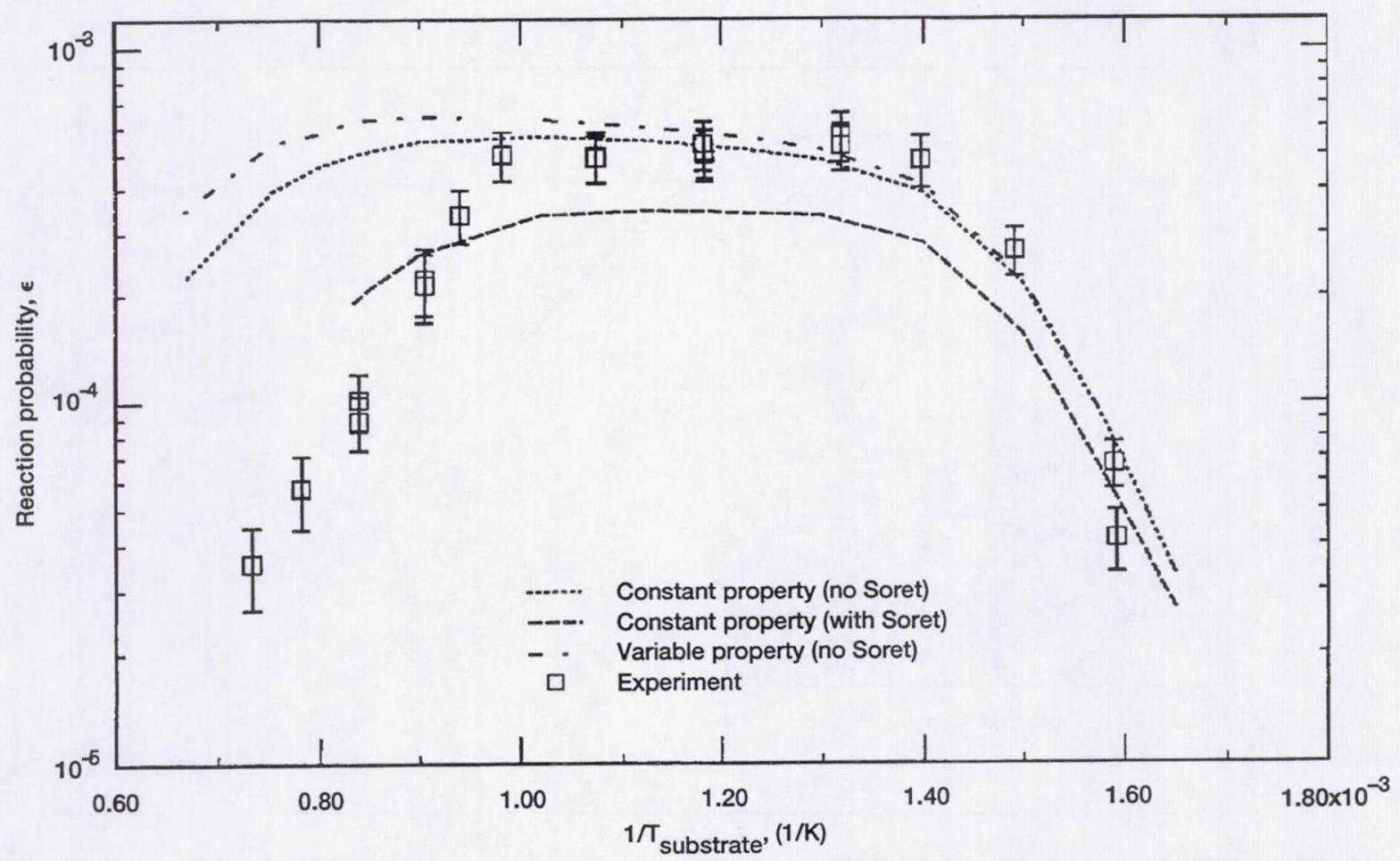

Figure 5.-Comparison of predicted deposition rates (including both gas and surface kinetics) with experimental data. 


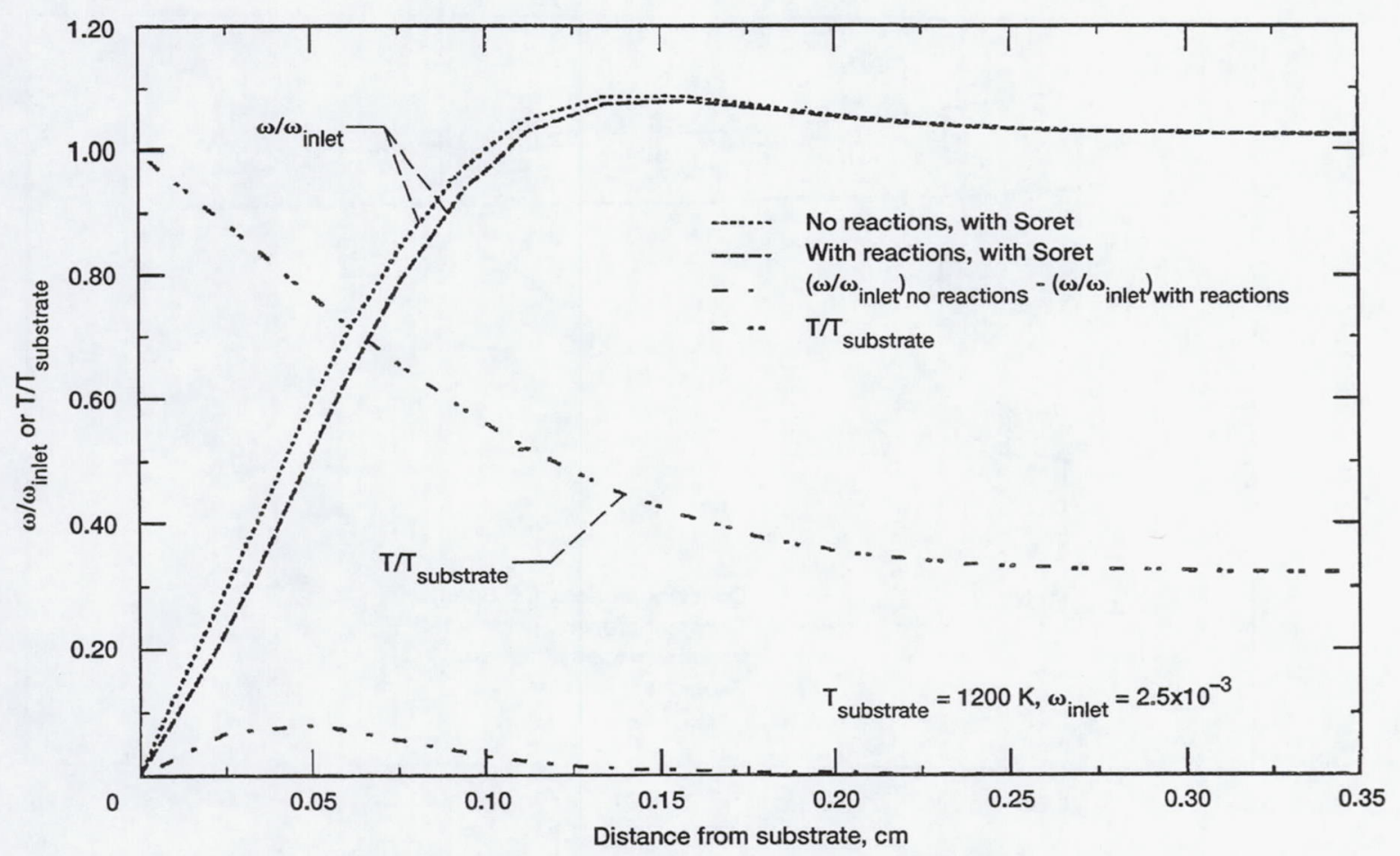

Figure 6.-The effect of gas phase reaction on mass fraction profile at $1200 \mathrm{~K}$. Soret effect is included.

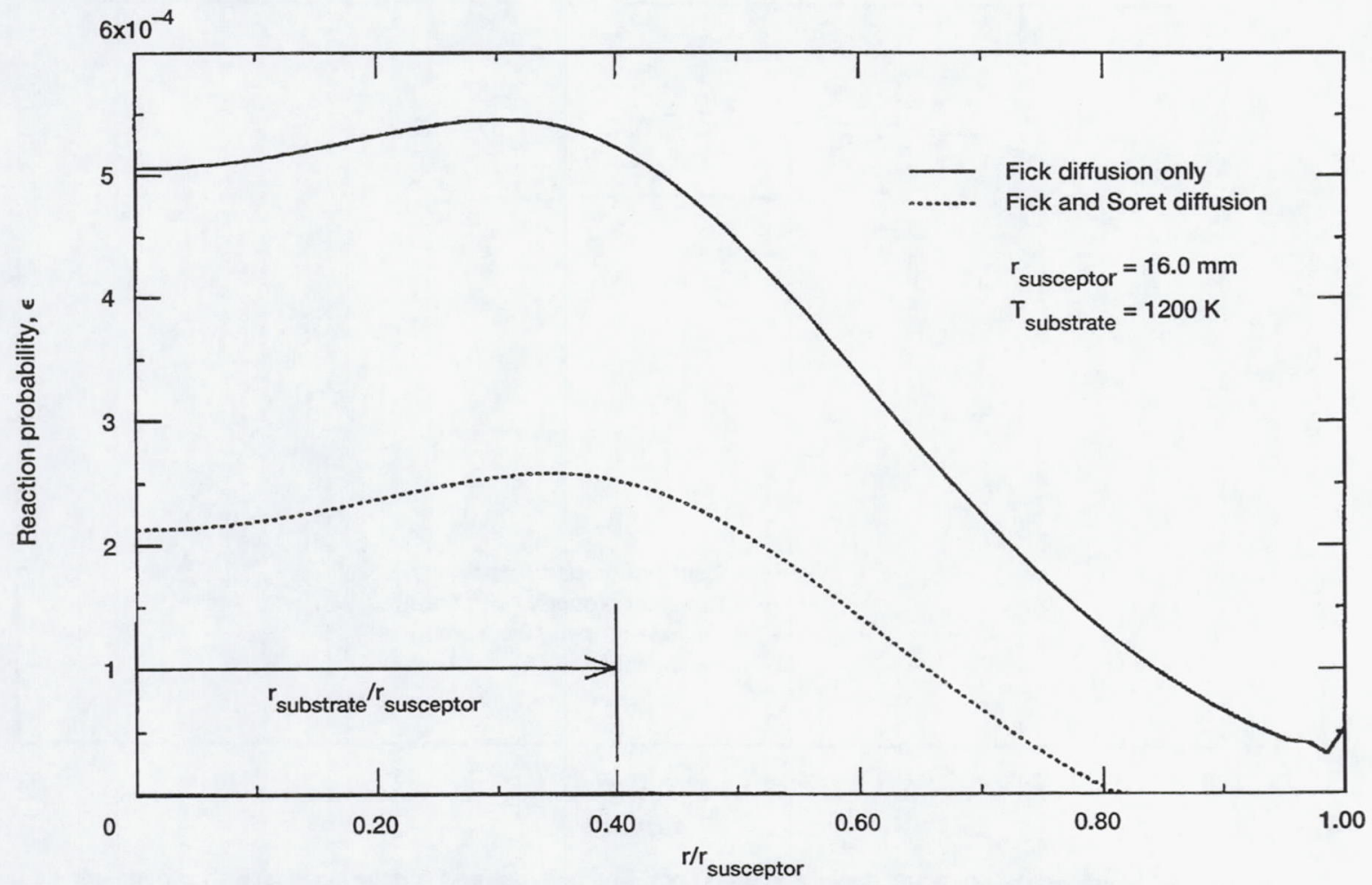

Figure 7.-Radial variation of predicted deposition rates across susceptor surface. 
Public reporting burden for this collection of information is estimated to average 1 hour per response, including the time for reviewing instructions, searching existing data sources, gathering and maintaining the data needed, and completing and reviewing the collection of information. Send comments regarding this burden estimate or any other aspect of this Davis Highway, Suite 1204, Arlington, VA 22202-4302, and to the Office of Management and Budget, Paperwork Reduction Project (0704-0188), Washington, DC 20503.

\begin{tabular}{|l|c|c|c|}
\hline 1. AGENCY USE ONLY (Leave blank) & $\begin{array}{c}\text { 2. REPORT DATE } \\
\text { June } 1994\end{array}$ & $\begin{array}{r}\text { 3. REPORT TYPE AND DATES COVERED } \\
\text { Technical Memorandum }\end{array}$ \\
\hline
\end{tabular}

4. TITLE AND SUBTITLE

5. FUNDING NUMBERS

Numerical Analysis of an Impinging Jet Reactor for the CVD and Gas-Phase Nucleation of Titania

6. AUTHOR(S)

WU-962-22-00

Suleyman A. Gokoglu, Gregory D. Stewart, Joshua Collins, and Daniel E. Rosner

7. PERFORMING ORGANIZATION NAME(S) AND ADDRESS(ES)

8. PERFORMING ORGANIZATION REPORT NUMBER

National Aeronautics and Space Administration

Lewis Research Center

Cleveland, Ohio 44135-3191

E-8905

9. SPONSORING/MONITORING AGENCY NAME(S) AND ADDRESS(ES)

10. SPONSORING/MONITORING AGENCY REPORT NUMBER

National Aeronautics and Space Administration

Washington, D.C. 20546-0001

NASA TM-106619

\section{SUPPLEMENTARY NOTES}

Prepared for the 1993 Fall Meeting sponsored by the Materials Research Society, Boston, Massachusetts, November 29-December 3, 1993. Suleyman A. Gokoglu, NASA Lewis Research Center; Gregory D. Stewart, Ohio Aerospace Institute, 22800 Cedar Point Road, Brook Park, Ohio 44142; Joshua Collins and Daniel E. Rosner, Yale University, Chemical Engineering Department, New Haven, Connecticut 06520-8286 (work funded by NASA Training Grant NTG5-0377). Responsible person, Suleyman A. Gokoglu, organization code 6740, (216) 433-5499.

12a. DISTRIBUTION/AVAILABILITY STATEMENT

12b. DISTRIBUTION CODE

Unclassified - Unlimited

Subject Categories 31 and 23

\section{ABSTRACT (Maximum 200 words)}

We model a cold-wall atmospheric pressure impinging jet reactor to study the CVD and gas-phase nucleation of TiO2 from a titanium tetra-iso-propoxide (TTIP)/oxygen dilute source gas mixture in nitrogen. The mathematical model uses the computational code FIDAP and complements our recent asymptotic theory for high activation energy gas-phase reactions in thin chemically reacting sublayers. The numerical predictions highlight deviations from ideality in various regions inside the experimental reactor. Model predictions of deposition rates and the onset of gas-phase nucleation compare favorably with experiments. Although variable property effects on deposition rates are not significant $(\sim 11 \%$ at $1000 \mathrm{~K})$, the reduction of rates due to Soret transport is substantial $(\sim 75 \%$ at $1000 \mathrm{~K})$.

\section{SUBJECT TERMS}

Chemical vapor deposition; CVD; Metal-organic chemical vapor deposition; MOCVD; Titania; Gas phase nucleation; Impinging jet reactor; Modeling

15. NUMBER OF PAGES

16. PRICE CODE

\begin{tabular}{|c|c|c|}
\hline $\begin{array}{c}\text { 17. SECURITY CLASSIFICATION } \\
\text { OF REPORT } \\
\text { Unclassified }\end{array}$ & $\begin{array}{c}\text { 18. SECURITY CLASSIFICATION } \\
\text { OF THIS PAGE } \\
\text { Unclassified }\end{array}$ & $\begin{array}{c}\text { 19. SECURITY CLASSIFICATION } \\
\text { OF ABSTRACT } \\
\text { Unclassified }\end{array}$ \\
\hline
\end{tabular}

